\title{
As mulheres no movimento de arte pornô
}

\section{Cynthia Dorneles'}

Resumo: A autora reflete sobre a contribuição das performers, artistas e poetas ao Movimento de Arte Pornô e descreve sua própria participação neste movimento de vanguarda brasileiro do início dos anos 80 .

Palavras-chave: Arte. Poesia. Performance. Pornografia.

\section{Women in the porn art movement}

\begin{abstract}
The author reflects on the contribution of female performers, artists and poets to the Movimento de Arte Pornô (Porn Art Movement) and describes her own participation in this Brazilian vanguard movement of the early 1980s.
\end{abstract}

Keywords: Art. Poetry. Performance. Pornography.

I Cynthia Dorneles é poeta, escritora, compositora, intérprete, psicóloga e fotógrafa. Participou da antologia A Ebulição da Escrivatura, revista Escracho, A Amante Ideal, Os 1001 E-Mails Sherazade Conta Histórias Eróticas a Um Marujo Solitário. Universidade Federal do Rio de Janeiro, Largo São Francisco de Paula, Rio de Janeiro - RJ, 20051070. E-mail: cynthiadorneles@gmail.com. ORCID: https://orcid.org/0000-0003-0859-7756. Lattes iD: http:// lattes.cnpq.br/1525765215176087. Rio de Janeiro, Brasil. 
O presente trabalho pretende revisitar um dos movimentos mais radicais dos anos 80, o Movimento de Arte Pornô (MAP) e seu braço performático, a Gang. Meu foco neste ensaio é a participação feminina no movimento, que do Rio de Janeiro e de São Paulo se espalhou por todo o país.

Este recorte analítico originou-se das entrevistas que realizei em $2019^{1}$, nas quais tanto Eduardo Kac quanto Cairo Assis Trindade (1946-2020) afirmam que apesar do número de assinaturas femininas ao manifesto ter sido pequeno, a importância destas mulheres foi fundamental. O movimento e a Gang, segundo os criadores do movimento, jamais teriam sido possíveis sem elas.

Que mulheres eram estas que contribuíam para um movimento cujo título subvertia o pornográfico em plena ditadura militar brasileira? Pergunta sem respostas simples, que começa com a constatação de ser uma geração de mulheres que surge vinte anos depois do advento da pílula anticoncepcional, que nos permitiu separar a reprodução da sexualidade.

A pílula anticoncepcional possibilitou que as mulheres pudessem viver sua vida sexual sem medo de engravidar e, portanto, explorar melhor seu corpo e seu prazer (Bandeira \& Melo, 2009). Estas filhas da pílula - e já após a revolução dos costumes do movimento hippie, que por sua vez também foi facilitado exatamente pela invenção da pílula — se deram a liberdade não apenas física, de explorar seu prazer, como também a de um fruir artístico e filosófico que resultou no engajamento com um movimento artístico original, que foi o Movimento de Arte Pornô. Tal feito já seria notável em países que vivessem em democracias. Num país que vivia sob ditadura militar, como o Brasil, com costumes extremamente conservadores, a ativa e decisiva participação de mulheres no Movimento de Arte Pornô ganha dimensões épicas.

Este artigo faz uma leitura de alguns dos trabalhos acadêmicos produzidos sobre o movimento, aos quais se agregam entrevistas que realizei com as lideranças do movimento. A estas, adiciono algumas memórias pessoais, pois fiz parte do movimento, tanto atuando na Gang quanto compondo canções, escrevendo, cantando, e fazendo grafites.

1 Entrevista concedida por Eduardo Kac em 24/11/2019 e por Cairo Assis Trindade em $17 / 11 / 2019$ 
O artigo está estruturado em três seções. Na primeira, exponho as concepções filosóficas e artísticas que estruturaram o movimento e o diferenciavam do que comumente se definia como pornográfico. A segunda apresenta a Gang, seus personagens, escritos e ações. Na terceira, evoco memórias e faço algumas reflexões sobre minha participação no Movimento de Arte Pornô.

\section{Concepções Filosóficas e Artísticas do Movimento}

Antes de mais nada, faz-se necessário explicar que o núcleo do trabalho do Movimento de Arte Pornô jamais foi o que classicamente se entende por pornográfico, que é a representação sexual visando excitar o público. Como afirmou Fernanda Nogueira, "...membros da Gang e do MAP assumiram a poesia e a literatura como territórios a serem pervertidos por meio de um projeto burlesco rebelde. Com o slogan "revolução e prazer", tanto suas ações quanto seus poemas procuravam criar um novo léxico, uma "gramática libidinal" para liberar a sensualidade, subverter a linguagem e se solidarizar com as minorias" (2015, p.22).

O Movimento tinha uma dimensão política, uma dimensão pansexual — era a palavra que o MAP usava na época. A explicação para o uso da palavra pornô: "Escolhi a palavra "pornô" de maneira consciente e séria, como emblema de transformação do proibido em uma plataforma socialmente aberta e criativa. Ao mesclar o que era tradicionalmente considerado sublime (arte) com o que socialmente era tratado como abjeto (pornografia), produzi uma nova síntese" (Kac, 2013, 38)

A definição que o dicionário Aurélio da Língua Portuguesa nos traz sobre pornografia possui três significações principais: 1. tratado acerca da prostituição 2. figuras, fotografias, filmes, obras literárias ou de arte relativos a, ou que tratam de coisas ou assuntos obscenos ou licenciosos, capazes de motivar ou explorar o lado sexual do indivíduo 3. Devassidão, libidinagem.

O Movimento de Arte Pornô foi muito mais do que isto, dado que tangenciou estas possibilidades, mas não as abraçou como principais focos de produção. O Movimento de Arte Pornô transformou a linguagem da pornografia em instrumento de liberação estética e política. 
Alguns elementos eram notáveis no trabalho da Gang, que colocava em cena o que se escrevia e produzia no cenário mais amplo do Movimento. Um deles era o uso de palavrões. Nas performances da Gang de Arte Pornô, os palavrões ocupavam um lugar de honra, mas sua aplicação ia muito além da poesia fescenina ${ }^{2}$. Há diversos exemplos de incursões poéticas no obsceno tanto na poesia iâmbica de Arquíloco quanto em Catulo ou Marcial, na Priapéia ou na Musa Puerilis de Estratão. Porém vale ressaltar que a ideia de obsceno muda com o tempo e que é fundamental analisar as obras de um poeta dentro de seu contexto histórico e social. Sem contextualizar, as análises podem facilmente incorrer no erro.

(...) uma compreensão mais ampla das sociedades grega e romana é necessária para enquadrar devidamente a obra de Arquíloco, Catulo ou Marcial. Ao mesmo tempo, a violência com a qual esses poetas infundiam suas obscenidades (como acusações de homossexualidade passiva e traição conjugal) e as imagens de estupro, bestialidade e mutilação que recheiam a Priapéia evidenciam o quanto estas obras são drasticamente diferentes do Movimento de Arte Pornô, no qual o léxico obsceno é conscientemente investido com um programa progressivo de política do corpo (Kac, 2013, p. 35).

Vale lembrar que a poesia fescenina não desafiava a noção de obsceno e usava imagens que aludiam à violência e submissão sexual. Já o uso dos palavrões no trabalho artístico do MAP e das apresentações da Gang questionava e desconstruía hábitos e falas. Não era apenas para rir nem tampouco para excitar, como acontecia na poesia fescenina. O que na poesia convencional nunca foi de bom tom, como usar palavras chulas, na Gang estas imperavam e propunham comportamentos libertários desconstruindo seus usos coloquiais. $\mathrm{E}$, ao contrário da poesia fescenina, que através dos tempos foi ficando mais violenta, a poesia pornô tinha como proposta o prazer, a liberação e a igualdade em vez do sexo como elemento agressivo e opressor. Além disso, o MAP também produzia obras de artes plásticas com o mesmo ímpeto. Este conjunto de fatores causavam impacto e diferenciavam o MAP dos seus antecessores, por assim dizer, que haviam usado palavrões em poesia.

2 A palavra 'fescenina' vem de Fescenia, uma cidade cuja localização exata é desconhecida (possivelmente Narce ou Corchiano, na Itália) mas que era situada na Etrúria, antiga região na península itálica antes da era cristã. Lá os lavradores declamavam versos licenciosos durante festivais após as colheitas. A poesia fescenina eventualmente foi desenvolvida na sátira e no drama cômico romano. 
A Gang era o braço performático do Movimento de Arte Pornô. Nas apresentações, usava o corpo com gestuais que pela caricatura e movimento causavam o riso, a reflexão, ou o incômodo que mudam o estado de espírito do expectador. O uso do humor para ao mesmo tempo fazer uma crítica e propor uma transformação social era constante.

No rastro destas ações transformadoras do humor usadas nas performances da Gang, subvertia-se a estigmatização que bestializa o humano, como chamar a mulher por exemplo de "piranha" ou o homem de "viado", um uso muito comum em todo o país. Buscava-se quebrar esta atitude com poesia. O clássico poema de Bráulio Tavares (sem título), publicado no zine Gang n.2 (1981), serve de exemplo desta abordagem e é emblemático do Movimento de Arte Pornô:

\author{
não sou viado \\ muitos são \\ sem terem dado \\ eu sou é homem \\ que o digam \\ os que me comem
}

O uso de uma expressão estigmatizante reverberava ao redor de uma estrutura verbal dando sentidos opostos à expressão popular original e o resultado então era o choque, a surpresa, a saída do piloto automático que apenas repete um sentido. Outro clássico do MAP, e igualmente exemplar, é o poema Encontro, de Eduardo Kac - publicado em seu livro Nabunada não Vaidinha? (1981) - que subverte um dos insultos mais usados no Brasil:

\author{
vá se fuder \\ disse um ao outro \\ vá se fuder \\ disse o outro ao um \\ descobriram a felicidade \\ em seu lugar comum
}


Este processo de questionamento do uso das palavras e do palavrão na língua brasileira era um procedimento literário novo que o Movimento de Arte Pornô inventou e consagrou.

O poema Filosofia, de Eduardo Kac, também publicado no zine Gang n.2, é um destes poemas-síntese e encarna a filosofia do MAP:

pra curar amor platônico

só uma trepada homérica

O MAP não tinha nada a ver com o que usualmente se entende por pornografia, ou seja, a indústria do obsceno, que costuma ser violenta, desumanizante, misógina.

$\mathrm{O}$ ato sexual podia até ser descrito no MAP, mas seu sentido era invertido e transformado num outro elemento, um libelo à imaginação, à inovação estética e à espontaneidade. Era um olhar lúdico sobre os comportamentos sexuais e hábitos do cidadão comum no Brasil. As obras do MAP modelavam, configuravam uma sociedade progressista, aberta, liberta, não só no sentido sexual, mas no sentido social mais amplo.

\section{A Gang e as Personagens Femininas}

Em 1980, o "verão da abertura" — como foi nomeado pela mídia nacional — tinha algo de festa no ar, um convite a se pensar, como se diria hoje, "fora da caixa." Em 1980, a Gang, criada por Eduardo Kac e Cairo Assis Trindade, ocupou a praia de Ipanema em apoio às moças que haviam sido agredidas por banhistas por fazerem topless. Era o Topless Literário, o começo do Movimento.

Em fevereiro de 1980, Verônica Maieski, naquele momento com dezessete anos, protestava a favor da liberdade sobre seu próprio corpo fazendo topless nas areias de Ipanema. Ela estava com as amigas Maria Autuori e Isabel Amorim quando foram violentamente hostilizadas por frequentadores da praia. Elas foram cercadas por mais de cem homens e atacadas com copos cheios de areia e latas de cerveja. Resultado previsível numa sociedade machista, patriarcal e conservadora como a brasileira: Verônica é quem acaba sendo presa. (Nogueira, 2015, p. 19) 
Figura 1

Passeata da Gang, na comemoração aos 60

anos da Semana de

Arte Moderna, 1982

Fotografia

Belisário França

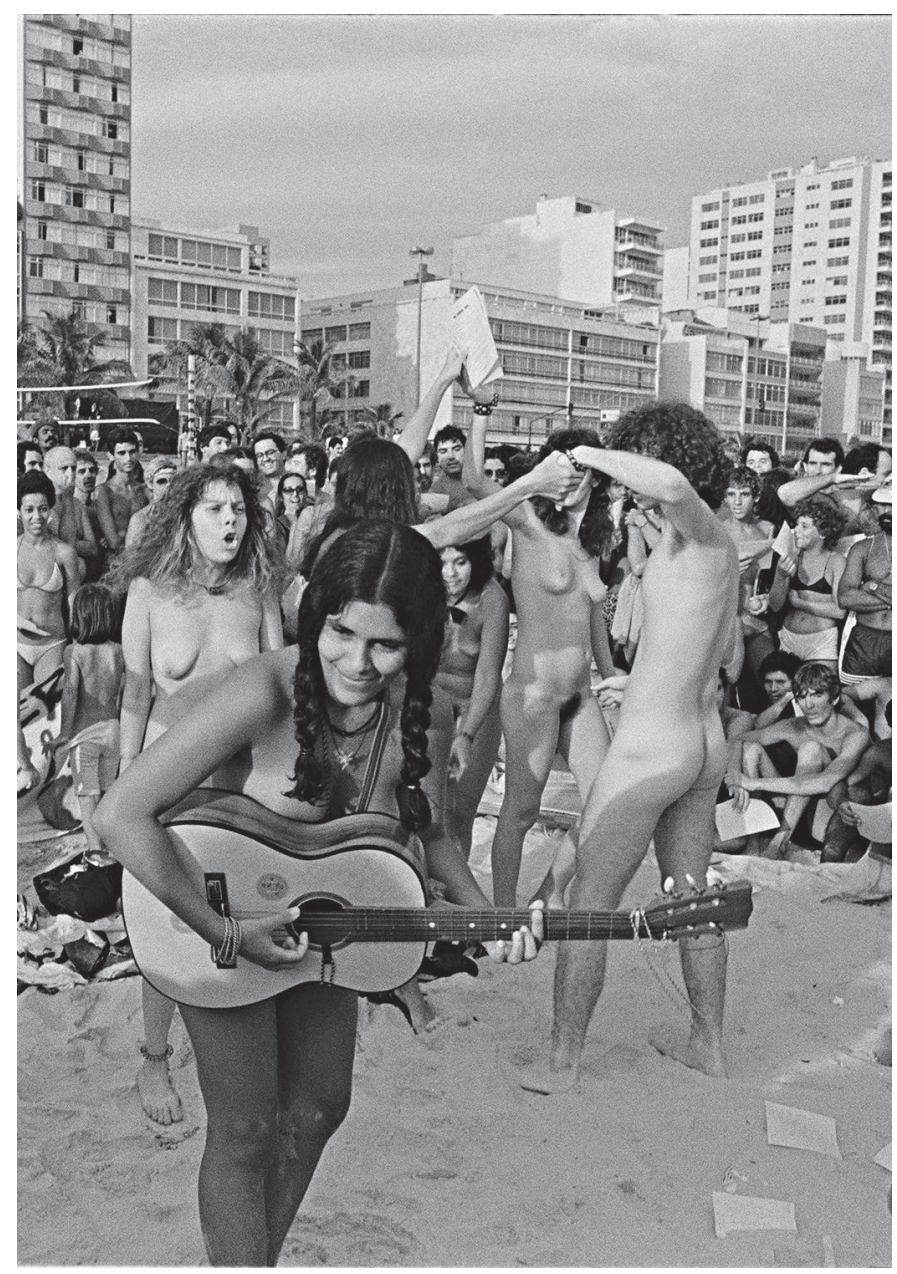

Afinal, se homens podem tomar sol sem sutiã porquê as mulheres não? $O$ que estava em discussão era o que seria ato ofensivo ao pudor, que pudor era este que aceitava coisas como o fio dental, mas não aceitava o peito desnudo feminino. Pudor seletivo? Pitoresco pudor que aceitava o peito masculino desnudo e o das mulheres não.

A imprensa em geral fazia extremo alarido sobre o topless. Falavam de celebridades que faziam topless em Saint-Tropez e noticiavam as celebridades no mundo que aderiam. No exterior, o topless era tratado como uma espécie de moda glamorosa. Entretanto, alguns jornalistas e comentaristas que escreviam nas colunas de jornais debochavam das mulheres que o praticavam aqui. O romancista capixaba José Carlos de Oliveira, na crônica "O Topless E O Leão Faminto," escreveu que as moças que faziam topless eram "garotas moderninhas, intelectuais rebeldes, profissionais do corpo" (Jornal do Brasil, 03/02/1980). Não foram poucos os que trataram do assunto em 1980. 
Em 23 de janeiro de 1980, por exemplo, no Primeiro Caderno do Jornal do Brasil, é noticiado que a Secretaria de Segurança não proibirá o topless nas praias do Rio, mas que reprimir ou não "compete à autoridade policial da jurisdição onde ocorrer tal prática". E no dia 25 do mesmo mês, ainda no Jornal do Brasil, a pérola de que em Belém uma moça pediu ao juiz para que pudesse fazer topless, e o advogado Raymundo Rayol disse que acataria o pedido porque "a moça tem seios muito bonitos. Se fossem feios não pegaria o caso". No dia 26 de janeiro de 1980, na página 3 do mesmo jornal, saiu a notícia de que vendedores de mate gritavam que uma moça fazia topless e uma multidão cercou a moça, que reagiu recolocando o sutiã enquanto a multidão aplaudia.

A imprensa ficou obcecada com o assunto. Uma das moças que faziam topless disse a respeito que: "só junta gente quando chegam os repórteres" (Jornal do Brasil, 04/01/1980, $1^{\circ}$ caderno, "Dia de Sol Enche as Praias"). A avidez com que os jornais e revistas faziam questão de retratar cada peito desnudo rendeu crônicas e situações constrangedoras para as praticantes de topless, que com frequência sofriam agressões verbais e físicas.

Depois que as moças foram agredidas e que, em solidariedade, Eduardo Kac e Cairo Trindade ocuparam a praia com a proposta do Topless Literário, poetas e artistas de todo o Brasil assinaram o manifesto de Arte Pornô, escrito pelos dois em 1980. As atividades organizadas do Movimento terminaram após a performance Interversão, com todos nus, realizada em fevereiro de 1982 na praia de Ipanema. No Jornal do Brasil, dia 16 de fevereiro de 1982, Zózimo Barrozo do Amaral publicou em sua coluna vários comentários sobre a performance (que incluiu uma passeata nudista). Esta coluna está registrada, com fotografias, na revista Escracho, de Eduardo Kac, publicada em 1983. Vários órgãos da imprensa cobriram esta performance, como a revista Visão (15 de março de 1982), que a ela dedicou página inteira.

Dos poetas e artistas que assinaram o manifesto, sete eram mulheres. Eu era uma delas. Darei especial atenção a esta participação feminina, e reconstituirei alguns passos do MAP e seu propósito artístico-filosófico por considerar que este Movimento precisa ser resgatado no Brasil. Hoje, o Movimento de Arte Pornô parece ser mais conhecido internacionalmente do que aqui no país em que se originou.

De 1980 a 1982, o grupo se apresentava nas ruas, nos bares, nas praias. Foram produzidos livros individuais e coletivos. Revistas foram publicadas. Foram 
feitos grafites e performances usando diversos elementos que iam desde a poesia mais popular até poemas visuais, fotos, canções, poemas-objeto e esculturas. As intervenções na imprensa se multiplicaram.

O que o Movimento de Arte Pornô realizou coletivamente entre 1980 e 1982 alinha-se com aquilo que se tornou conhecido, muitos anos depois, como "pós-pornô". O termo, popularizado por Annie Sprinkle em 1988, designa geralmente obras sexualmente explícitas que oferecem uma crítica do sexo normativo e das representações de gênero e produzem um campo cultural politizado composto de textos e imagens alternativos, lúdicos e subversivos". (Kac, 2013, p. 47)

O manifesto Pós Pornô Modernista de 1989, escrito por Veronica Vera e assinado pela própria Sprinkle mais Candida Royalle e Frank Moore, entre outros, defende coletivamente este campo que reúne criticas, textos e imagens que subvertem as convenções de sexo e gênero. Uma nova estética que o Movimento de Arte Pornô, nascido no Brasil, deu origem anos antes, com instigante posicionamento pansexual e como fruto da inovação poética e visual de Eduardo Kac aliadas ao conhecimento teatral e literário de Cairo Assis Trindade.

Das sete mulheres que assinaram o manifesto, Teresa Jardim, Sandra Terra, Ana Miranda e eu éramos não apenas participantes do Movimento como também das apresentações do grupo Gang. Leila Míccolis e Reca Poletti participaram do Movimento e das publicações, sendo que Leila Míccolis teve papel central no encontro de Eduardo Kac e Cairo Trindade, além de contribuir ativamente de outras formas. Sem Leila, não teria existido nem o Movimento, nem a Gang, pois foi através dela que eles se conheceram. A artista plástica Cecília, de Minas Gerais, contribuiu com desenhos.

Escreverei primeiro sobre as que não podem mais dar seus depoimentos, Sandra Terra, já falecida, e Deise Trindade que se encontra doente.

Sandra Terra (1961-1997) era do município de Macaé, localizado a cerca de 160 quilômetros do Rio de Janeiro. Ela publicou o livro Lady Bagaceira (1981) com seus poemas pornôs e participou na Antolorgia: Arte Pornô da Editora Codecri (Kac \& Trindade, 1984). Em 1989 mudou-se para Sana, um distrito de Macaé. Na Gang, ela era a Lady Bagaceira. Participou de trabalhos ligados à cultura de Macaé. Faleceu em 1997, vítima de HIV, aos 36 anos. De sua autoria, o poema Ninfomaníaca, publicado na Antolorgia: 
Trepo com tudo

e com todos

tarada por opção

gozo gozo gozo

e nunca perco o tesão

Sandra era uma força da natureza - ai de quem resolvesse criar caso com ela. Mulher guerreira, sabia brigar.

Denise Trindade, nascida em 1961, Porto Alegre, foi casada com Cairo Assis Trindade, com quem tem um filho e uma filha, que eram pequenos na época do MAP. Tornou-se atriz e Cairo acabou incentivando-a a participar. Nas apresentações, era a Princesa Pornô, companheira e amante do Rei da Sacanagem.

Publicou os livros Sessão Cabacinho, Book New Look e Mulheres em Transe, este em co-autoria com Kyvia Rodrigues. Em seu depoimento registrado na Antolorgia, Denise (que mais tarde mudaria seu nome artístico para Denizis) escreve que, através das charges do livro Sessão Cabacinho - uma antropofágica paródia ao cartum "Amar é" - ela procurava liberar a sensualidade, subverter a linguagem e incorporar as minorias. Eis um exemplo, publicado em Gang n.1 (1980):

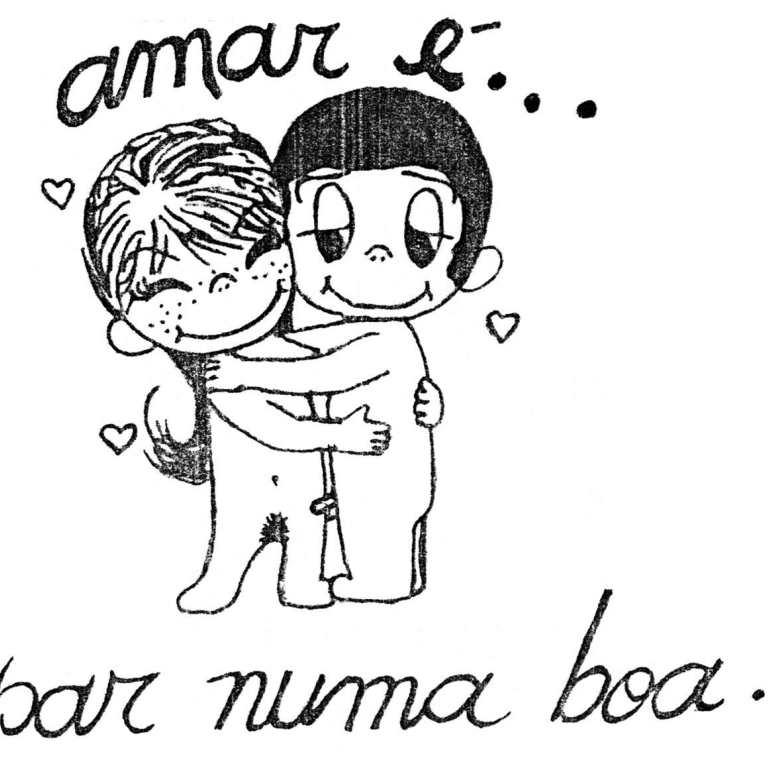


Entre 1980 e 1982, enquanto durou o Movimento de Arte Pornô, Denise vestia a camisa da Gang, mas um olhar mais atento poderia perceber que ela estava ali por amor ao seu companheiro. Era mais o amor do que a "causa". Tanto era assim que ela era bastante calada e aquiescia às decisões do grupo e sempre defendia as posições de seu companheiro. Após o término do MAP e da Gang no formato original, em 1982, Cairo e Denise mantiveram um trabalho teatral dando o nome Gang de Arte Contemporrânea ao novo grupo que fizeram. Quando a reencontrei, anos depois, me surpreendi. Denise, que sempre havia sido uma mulher belíssima em cena, era agora também uma pessoa "cheia de atitude" e dava aulas de Biodanza. Em 2015, Denise sofreu uma sequência de problemas graves de saúde - pneumonia, sepse e AVC isquêmico - que a impossibilitam de prosseguir seu caminho artístico. Foi terrível para mim vê-la doente. Denise tinha muito a oferecer para a cena da arte ainda.

O Movimento de Arte Pornô e a Gang ficaram esquecidos por uns trinta anos - quando em 2010 Eduardo Kac fez uma exposição individual de suas obras do período na Galeria Laura Marsiaj, no Rio de Janeiro, que reverberou na imprensa. Em seguida, Kac participou com obras da época do MAP em exposições coletivas em Paris (Underwood, Galerie 1900-2000, 2011) e Madrid (Perder La Forma Humana, Museu Reina Sofia, 2012, esta última com curadoria de Fernanda Nogueira, entre outros), trazendo assim o Movimento de Arte Pornô e a Gang de novo à cena, desta vez com repercussão internacional. Em 2014, o Museu de Arte do Rio inaugura a exposição Josephine Baker e Le Corbusier, Um Caso Transatlântico na qual são expostas algumas obras do Movimento de Arte Pornô; Fernanda Nogueira também participa na curadoria. Na ocasião, o museu organizou uma mesa redonda sobre o Movimento, na qual participei com Eduardo Kac, Bráulio Tavares e Ota.

Fiz duas entrevistas em novembro de 2019 para realização deste artigo. Uma com Cairo Assis Trindade e outra com Eduardo Kac. Ambos são unânimes em afirmar a importância das mulheres tanto no MAP quanto na Gang. Eduardo Kac destaca o papel central de Leila Míccolis no desenvolvimento do Movimento de Arte Pornô.

Leila Míccolis não participou das performances da Gang, mas está presente nos três números do zine Gang. Publicou artigos e entrevistas, como "Movimento de Arte Pornô, Embuste ou Revolução" (jornal Auê, 1981). Participa da revista Arsenal de Cultura no Ceará com Paulo Veras, Eduardo Kac e Hudinilson Jr., promovendo o MAP. O livro Maus Antecedentes é o livro 
dela dentro do MAP. Leila cita a Gang e o MAP em artigo sobre poesia e fotografia na revista Íris, na qual Paulo Klein dava espaço para Leila, Eduardo Kac e Glauco Matoso. Finalmente escreve o livro Jacarés e Lobisomens (1983) com Herbert Daniel que também inclui o MAP como pano de fundo. Leila Míccolis publicou através da sua Editora Trote a Antologia do Poema Pornô (Kac \& Trindade, 1981) e participou da Antolorgia: Arte Pornô, publicada pela Editora Codecri (Kac \& Trindade, 1984). Esta última inclui seu soneto Bons Tempos:

\author{
Namoro antigo: titia \\ na sala bordando um pano, \\ tomava conta, e inda havia \\ entre nós dois...um piano... \\ Pra se mostrar, a vigia \\ Tocava um rondó cigano, \\ tão mal, que ela enrubescia \\ se rias de algum engano... \\ Por fim, como despedida, \\ a mais ousada bravata: \\ o beijo na minha tez. \\ E após a tua saída, \\ Eu, titia, mais a gata, \\ Surubávamos as três...
}

Para Cairo, a peça chave foi Maria Amélia Mello, do Centro de Cultura Alternativa, que organizava a Feira de Poesia da Cinelândia, pois sem esta feira não teriam existido as apresentações em público e a iniciativa de transformar as poesias em performance. Sem as apresentações, Cairo acredita que teriam sido apenas mais um grupo de poesia num país que pouco valoriza a poesia.

Tanto Eduardo quanto Cairo pontuam também a importância da participação de Teresa Jardim. Foi com a adesão de Teresa que o grupo foi ganhando a dinâmica que seus idealizadores tinham em mente. Teresa Jardim junto ao grupo é uma presença cênica forte. A partir de serem um trio, conseguem imprimir ao grupo cenas ágeis com os ingredientes pelos quais tornaram-se conhecidos. Cairo era amigo pessoal de Teresa e havia sido seu professor de teatro anteriormente. Reconhecia nela um talento especial como comediante. 
Eis um típico poema de Teresa Jardim, que ela declamava nas performances da Gang, intitulado Na Moita:

\author{
botou tudo pra fora \\ meteu o pau \\ no corpo federal \\ e saiu todo faceiro \\ do banheiro \\ o soldado com o general
}

Teresa Jardim, filha de Reynaldo Jardim, conhecido poeta e jornalista, publica junto ao grupo Gang os livros A Dama da Bandalha e A bandalha-tesão $e$ revolução. Faz dezenas de apresentações com a Gang entre 1980 e 1982, período em que existiu o braço performático do MAP.

Depois da Gang, Teresa mudou-se para a região de São Pedro da Aldeia, em Friburgo. Teve sete filhos, uma neta e um casamento longevo com o pai das crianças, que faleceu em 2015. Pelo vídeo postado no YouTube (27 de junho de 2016), continua sendo uma senhora poética e ousada. No começo dos anos 80, mesmo já sendo um momento de relativa liberação, ainda era Ditadura, ainda se corriam riscos e a censura federal existia. Membros do governo cometiam atentados contra setores progressistas da sociedade. No vídeo ela comenta sua participação no Movimento de Arte Pornô com bastante alegria e desinibição.

Vale ainda mencionar que Reca Poletti contribuiu um poema, publicado em Antolorgia: Arte Pornô (Kac \& Trindade, 1984) e Alice Ruiz contribuiu um poema publicado em Gang n.3 e republicado em Antolorgia: Arte Pornô. Já Anna Miranda participou da performance Interversão, na praia de Ipanema, em 1982 e publicou um poema em Antolorgia: Arte Pornô. Ana Miranda era apaixonada pelo canto e cantava na Gang a música Kisuco de Pau. Mudou-se de volta para Teresina logo após à performance da Gang na praia de Ipanema, em 1982. Gostei muito de conhece-la, mas nossa convivência foi breve. De sua autoria, Curimatã:

\footnotetext{
Curimatã

Arfando muito

Tirou os peitos

Do sutiã
} 
Deu um pro filho

Outro pro jovem elegante

Depois deu os dois

Pra amante

\title{
Minha participação no Movimento de Arte Pornô
}

Eu fui a última pessoa que entrou na Gang original, esta que durou o tempo do Movimento de Arte Pornô, concluído em 1982 com a performance Interversão na praia de Ipanema. Pessoalmente, já tinha publicado poemas em algumas antologias. Adorava cantar e compunha canções com minhas próprias letras. Estava estudando Ciências Sociais, me especializando em Antropologia. No Instituto de Filosofia e Ciências Sociais da Universidade Federal do Rio de Janeiro-UFRJ, participava das assembleias e de reuniões dos grupos políticos que lá atuavam. Destes, o grupo que mais havia me mobilizado era um coletivo de mulheres feministas que acontecia na casa de uma delas.

\begin{abstract}
A partir de 1975 surgem os primeiros grupos feministas organizados, no sentido moderno do termo. Estávamos ainda em plena vigência do Al-5 e, para que eles tivessem podido formar-se, foi necessário o patrocínio direto das Nações Unidas. Fundam-se, então, neste ano, o Centro da Mulher Brasileira, no Rio de Janeiro e o Centro de Desenvolvimento da Mulher Paulista e nesse mesmo mês (outubro de 75) os meus dois livros acima citados [A Mulher na Construção do Mundo Futuro (Vozes, 1966); Libertação Sexual da Mulher (Vozes, 1970)] são proibidos pela Lei Falcão como pornográficos. E provavelmente como punição às feministas que começavam a organizar-se (Muraro, 1983, p.14).
\end{abstract}

Em 1979, o presidente Figueiredo aprovou a lei da anistia. Patrícia Casé, em outubro de 1979, fez topless na praia de Ipanema, seguida depois por outras que protestavam a favor da liberdade sobre o seu próprio corpo - cuja musa poderia ter sido Leila Diniz, que dez anos antes, em 1969, fez uma foto grávida de barriga de fora, um escândalo para a época. Neste mesmo ano ocorreu o festival Woodstock Music and Arts Fair, nos Estados Unidos - acontecimento marcante para a juventude mundial e particularmente a norte-americana, ao incendiar o campus universitário nos protestos contra a guerra do Vietnam. A literatura tanto nacional quanto internacional é limitada a respeito da presença feminina nestes eventos e, no caso brasileiro, praticamente ignora as mulheres no movimento hippie e nos acontecimentos explosivos da luta armada. Entretanto, as mulheres estiveram presentes em todos estes momentos. 
No Brasil, as feministas tinham como parte de suas bandeiras a contracepção e o direito ao aborto, sintetizados na frase Nossos corpos nos pertencem. Este mote, sem dúvida, teria eco na forma como a Gang levou adiante seus happenings, nos quais cada um usava seu corpo com a liberdade de quem sabe que vale tudo, contanto que seja com voluntária aquiescência consciente de cada um.

Uma das ações que meu grupo feminista propôs foi a de pichar pela cidade Nosso Corpo Nos Pertence. Eu derivei para O Prazer Só É Mau Para Quem Não Sente, que chamou a atenção de Eduardo Kac. Quando nos conhecemos, em 1981, conversamos sobre isto, pois eu havia adorado a pichação OVERGOZE que era dele - mas eu não fazia ideia disto. Um dos meus grafites no MAP foi Prazer pra Todas, combinando o símbolo da mulher com o do anarquismo, de forma que o círculo envolvia o A, fazendo, assim, referência a homens e muIheres (i.e., possibilitando a leitura simultânea das palavras 'todas' e 'todos').

Foi passeando pela Cinelândia em 1981 que vi pela primeira vez a Gang de Arte Pornô em cena. Fiquei encantada.

Era um grupo que fazia sentido para mim. Mais do que movimentos estudantis ou políticos, nos quais haviam casos notórios de participantes que falavam em revolução do proletariado, mas batiam em suas companheiras ou sonegavam pagamentos de pensões para filhos. Como alguém poderia falar em revolução e se permitir bater numa mulher? Ou deixar de assumir responsabilidade por seus filhos? Nos movimentos da esquerda tradicional algo parecia estar frouxo, distanciando discursos e práticas.

Minha busca pelo feminismo vinha como reação a contradições como estas. E o encontro casual com a Gang fechava com chave de ouro uma busca que tinha pela arte e pela possibilidade de mudança.

Neste espírito compus e cantei a música Sacanás que foi publicada no livro Antolorgia. Eis a letra:

\author{
Nem anjo nem demônio \\ Não nasci pra ser \\ senhora nem puta... \\ Dona do meu nariz \\ eu quero é ser feliz \\ Nosso amor não é impossível
}


mas também não tem futuro

somos um sonho

que alguém sonhou

e não se lembra mais

e agora pergunta

aonde estamos

nus por aí

Compus a música para a letra Trepada Trepidante de Eduardo Kac, emprestei minha saia rosa e meu batom para ele também. Fizemos juntos viagens e grafites. Eram tempos de pequenas, médias e grandes ousadias e eu estava ali para isso mesmo.

Apesar de a maioria das assinaturas do manifesto ser de homens, o grupo Gang em cena na praia de Ipanema em 1982 era de cinco mulheres e dois homens. Maioria feminina, portanto.

Lendo os poemas pornôs na Gang, vemos que havia espaço para estas vozes femininas se manifestarem com ímpeto e criatividade - como eu mesma sempre comprovava.

Foram homens que inventaram o Movimento e o grupo Gang, sem dúvida. Mas a existência do MAP e da Gang da forma como se deu foi possível porque nós, mulheres, tomamos parte disso ativamente. É importante mencionar também que parte significativa da pesquisa acadêmica em curso sobre o Movimento de Arte Pornô está sendo feita por mulheres. Além de Fernanda Nogueira, acima citada, Tie Jojima está fazendo dissertação de doutorado sobre o MAP no programa de História da Arte da The City University of New York (CUNY), em Nova lorque.

\section{O Que Veio Depois}

Em 1984 comecei a ter ataques de pânico e perdi contato com todos os membros tanto da Gang quanto do Movimento de Arte Pornô. Em 1990 nasce meu filho e voltei a encontrar Bráulio Tavares, porque nossos filhos estudavam na mesma escola. Foi no fim dos anos 90 que voltei a ter contato com Eduardo, Cairo e Denise.

Fui lutando para ficar bem e aos trancos e barrancos segui meu caminho. Me formei em Ciências Sociais pela Universidade Federal do Rio de Janeiro 
em 1982 e em Psicologia pela Universidade Santa Úrsula em 2010. Fiz mais poemas. Fiz shows de música com músicos profissionais. Escolhi musicar minhas poesias - para sempre influenciada pelas ideias de Eduardo Kac, que dizia que a poesia escrita em versos convencionais era apenas diluição, que a arte deveria ser sempre uma busca de inovação formal. Então eu busquei.

Escrevi livros, dentre eles o livro A Amante Ideal (Record; 2000), com o mote de que as mulheres devem realizar seus desejos sexuais, mesmo que seja com outra pessoa que não o marido. O livro foi colocado nas estantes de autoajuda. Mas poderia estar na estante de humor. Ou de pornografia. Não a pornografia clássica. Mas esta pornografia do Movimento de Arte Pornô. Esta que inverte sentidos e desconstrói os hábitos e costumes.

Sinto que está cada vez mais distante este mundo no qual cada um toma pé de seu lugar como narrador de sua própria história e questiona o que faz para encontrar seus valores. O ano de 1980 parece estar ou num passado remoto junto aos povos indígenas, que andavam nus sem medo de seus corpos, ou num futuro distante no qual as pessoas redescobrem o prazer de conviver sem barreiras de gênero. Seja como for, em qual tempo for, que poetas cantem sempre à liberdade, à luta e ao prazer.

\section{Referências}

ATAHUALPA, Marcelo. Novembro de poesia viva. Disponível em: <https:// www.facebook.com/events/1494568167368605>. Acesso em 16 de nov. de 2019.

BLUE, Ana. A operária da arte. Jornal A Voz da Serra. 2 de jul. de 2016. Disponível em: <http://acervo.avozdaserra.com.br/noticias/teresa-jardim-operaria-da-arte>. Acesso em 05 de mar. de 2020.

FERREIRA, Aurélio Buarque de Holanda. Dicionário Aurélio da Língua Portuguesa. 5 ed. Editora Positivo, 2010.

FISHER, Ernst. A Necessidade da Arte. 9 ed. Rio de Janeiro: Editora LTC, 2007.

FREUD, Sigmund. A Interpretação dos Sonhos. Rio de Janeiro: Editora Imago, 2001.

KAC, Eduardo. Luz \& Letra. Rio de Janeiro: Editora Contra Capa, 2004. 
KAC, Eduardo. O Movimento de Arte Pornô: a Aventura de uma Vanguarda nos Anos 80. Revista ARS número 22. Escola de Comunicação e Artes USP, 2013.

KAC, Eduardo; TRINDADE, Cairo Assis (org.). Antologia do Poema Pornô. Rio de Janeiro: Editora Trote,1981.

KAC, Eduardo; TRINDADE, Cairo Assis (org.). Antolorgia: Arte Pornô. Rio de Janeiro: Editora Codecri,1984.

MELO, Hildete; BANDEIRA, Lourdes. Gênero: Núcleo Transdisciplinar de Estudos de Gênero. Editora da UFF, 2012, p. 239.

MURARO, Rose Marie. Sexualidade da Mulher Brasileira. Petrópolis: Editora Vozes, 1983.

MUSEU REINA SOFIA. Perder La Forma Humana. Catálogo da Exposição. Espanha: Editora Mali, 2013, p. 282.

NOGUEIRA, Fernanda. Alianças de Corpos Vulneráveis. São Paulo: Edições SESC, 2015. 